\title{
Cerebellum in Neurological Disorders: A Review on the Role of Inter-Connected Neural Circuits
}

\section{Abstract}

Recent studies have indicated the additional role of cerebellum beyond motor coordination non-motor and socio-cognitive tasks. Exploration of cerebellar roles in timing and plasticity have been attributed specific roles in neurological conditions such as ataxia, severe disorders such as Parkinson's and epilepsy. Cerebellar dysfunctions elaborate the need of research on cerebellar circuitry and physiology to better understand neurological functions and dysfunctions. Structural and functional studies of cerebellum also implicate the connection between cerebellum with inter-connected circuits such as thalamo cortical and basal ganglia networks during motor and non-motor functions. In this review, we list some of recently perceived roles of cerebellum in information processing, neurological conditions in disorders.

Keywords: Cerebellum; Ataxia; Parkinson 's disease; Epilepsy; Neurological Disorders

Mini Review
Volume 6 Issue 2 - 2017
Arathi G Rajendran, Chaitanya Nutakki,
Hemalatha Sasidharakurup, Sandeep
Bodda, Bipin Nair and Shyam Diwakar*
Amrita School of Biotechnology, Amrita Vishwa Vidyapeetham
(Amrita University), India
*Corresponding author: Shyam Diwakar, Amrita School
of Biotechnology, Amrita Vishwa Vidyapeetham (Amrita
University), Amritapuri campus, Clappana PO, Kollam,
Kerala, 690 525, India, Email: shyam @amrita.edu
Received: December 14, 2016 | Published: February 16,
2017

\section{Introduction}

Recent advances in neuroscience encouraging the development of new technologies including anatomical explorations of 100 billion nerve cells, decoded activity patterns in neural circuits provided new information to understand the neurological conditions and their mechanistic basis [1,2]. Although until the end of $18^{\text {th }}$ century, the role of cerebellum was co-involved solely with motor coordination its role in motor function has been further explored [3] and has led to experiments and theories that now include cerebellum's contributions to cognitive processing and emotional control. Cerebellum receives sensory information as an input from the spinal cord and other parts of the brain and generates a motor movements as output. Cerebellar cortex inhibits and excites the motor control actions that are generated elsewhere in the brain [4] and have been associated to help maintain posture and balance, speech and movement coordination resulting from smooth muscle activity. Mossy fiber inputs have been known to carry information on the goal of a movement, sensory feedback about the states of the body and the sensory representations of external world, and the efferent copy of motor commands to granule cells [5]. Purkinje cells, mainly activated by parallel fiber inputs from granule cells, project to deep cerebellar nuclei, which further transmit information to downstream motor systems such as the ocular motor system, spinal cord and cerebral cortex via the thalamus.

\section{Prediction and correction using cerebellar internal models for ataxia}

Cerebellar damage results in uncoordinated, inconstant and dissymmetric movements known as ataxia causes mismatch between dynamics modeled by the brain and actual body dynamics resulting in ataxia condition. A study [6], It used both behavioral and computational approaches to demonstrate cerebellar patient movement deficits from the biased internal models. Mathematical modeling suggests bias in ataxic movements to be an internal misestimate of arm inertia. Another study [6] emphasized that an undamaged cerebellum is critical for maintaining accurate internal model of dynamics. In the case of Friedreich's ataxia, cerebellum was observed with significant loss of grey matter and white matter using voxel-based morphometry [7]. Studies on abnormalities related to brain connectivity and functions were reported earlier [8].

Structural and functional relationship of the major components of central nervous system includes coordination of loco motor movements in cerebellum [9] is one among five properties. More than a century later, a study [10] explained electro physiological properties of cerebellar learning behavior neural circuit and predicted that synaptic efficacy decreases when the parallel fibers and climbing fibers are activated. Some studies focus on cerebellar function as a sensory motor control system modeled as embedded forward controllers and internal structures for error prediction and learning [11-15] based on the connection statistics of the circuit, the geometry and the connectivity of the circuit [16].

Recent imaging studies have shown that the cerebellar outputs to a vast area of neocortex and have reciprocal connections with the basal ganglia $[17,18]$. Cerebellar cortex models $[19,20]$. helps to understand the structure function relationship between neurons, impact of the membrane properties on spikes, and the role of synaptic plasticity and synaptic dynamics during spike-time dependent plasticity $[21,22]$ as well as impacting various input parameters on computing signals and transferring information $[10,23,24]$ which depend on the position and orientation of the robotic manipulator [25-28]. Understanding the cellular mechanisms of the encoding information by the cerebellum ideally includes identifying what the properties of synaptic inputs to the nuclei are, how the excitability of neurons is affected by these stimuli, and which patterns of activity modify synaptic inputs and spike outputs to yield motor coordination and learning 
[29]. Associated with physiological roles, cerebellar cortex, deep cerebellar nuclei and the inferior olive are the three main hubs of the cerebellar circuit. Each of these circuits involves a relatively modest number of cell types with synaptic connectivity between the hubs being highly parallel and modular. Cerebellum has an important role in movement disorders in association with basal ganglia (BG) since, the functions of both sub cortical structures are almost same. Recent findings have associated cerebellum with neurological disorders and conditions such as Parkinson's disorder, ataxia, dyskinesia and degradation of movement and increased tremors.

\section{Cerebellum as target in Parkinson's disease}

Parkinson's disease (PD) is a neurodegenerative disorder that affects motor and cognitive behavior through cerebellothalamo-cortical circuits. Multiple functional neuro imaging studies demonstrated hyper activation in the cerebellum in patients with Parkinson's disease [30-35]. From a computational angle, it has been suggested that the cerebellum is specialized for supervised learning based on the error signal encoding whereas basal ganglia are specialized for reinforcement learning (RL) based on the reward signal encoded in the dopaminergic fibers from the substantianigra and cerebral cortex is specialized for unsupervised learning based on plasticity between cortical areas. Damage to the basal ganglia or cerebellar components of circuits with motor areas of cortex have been known to lead to motor symptoms, whereas damage of the sub cortical components of circuits with non-motor areas of cortex has been known to cause higher-order deficits [36].

In animal models of PD, oscillatory activity at tremor frequencies have been recorded in motor thalamus along with this hyper activations in some other regions such as motor cortex and striatum and weak striato-thalamo-cortical and striato-cerebellar connectivity. Previous studies have shown that disynaptic connections transmit STN activity to cerebellar cortex $[37,38]$. The motor signs and cerebellar activation have been known to be improved by normalizing the functions of cerebellum through various treatment methods including surgical treatment and deep brain simulation [39-42]. Deep brain stimulation of the STN is also an effective treatment for the movement symptoms of PD $[43,44]$. Deep brain stimulation may alter STN activity and reduce $S T N$ abnormal output to the cerebellum.

\section{Lesional cerebellar Epilepsy}

Overthelastdecades, advancesinknowledgeon epileptogenicity and seizure spread have led to better understanding of the role of sub cortical structures during epilepsy [45] myoclonic seizure is most common in lesional Cerebellar Epilepsy, which has been reported in patients [46-50]. A study [51] suggested that propagation of epileptic activity from cerebellar hematoma may cause myoclonus. This epileptic nature of myoclonic 'seizures' is further braced by evidences from invasive EEG studies. Myoclonic seizures occurs with dystonia, which causes sustained muscle contraction, repetitive movements and abnormal postures [52]. Though there have been extensive reports of dystonia associated with cerebellar lesions, the pathophysiology is not clear. However the structural and functional interactions between the cerebellum and basal ganglia circuits plays a major role $[53,54]$ In this movement disorder dystonic, movement disorder has been associated to both basal ganglia and cerebellar circuits, which forms multi synaptic loops with cerebral cortex [55].

Absence seizures are kinds of epileptic seizures which lasts for few seconds and characterized by unconsciousness or absent state and appear to be initiated in a putative control initiation site with expression of $5-9 \mathrm{~Hz}$ due to decreased GABAA receptor function [45]. Absence seizures have been associated to abnormal electric activity in reciprocally connected thalamo-cortical areas [52-56].

The abnormalities related to white matter reflects in increased cortical excitability and cause cognitive, linguistic and behavioral/ emotional deficit in both during and between seizures [57]. Related work has been done by [58], using this Diffusion Tenser Imaging (DTI) to quantify structural abnormalities of Default Mode Network (DMN) region in CAE patients indicated structural impairments in DMN regions in CAE patients experiments [59]. This will be indicated that the cerebellum is a powerful modulator of temporal lobe epilepsy. The study based on mouse models used online seizure detection and responsive opt genetic interventions to understand the role of cerebellum in spontaneous temporal lobe seizures indicated that the cerebellum inhibited spontaneous temporal lobe seizures.

\section{Conclusion}

Recent advances in cerebellum research has helped augment understanding functions related to both motor and cognitive domains allowing evaluating the effectiveness of certain treatments for neuro-disorders. Possibility that the cerebellum having the feedback internal models (forward and inverse) retain and integrate the system exploiting mechanisms of motor learning and control.

Cerebellar neuronal disorders are being treated using transcranial direct current stimulation (tDCS), deep brain stimulation and surgical interventions promising solutions towards Parkinson's, dystonia, essential tremor and cerebellar ataxia. Such methods also influence study of non-motor functions like pain experiences, nociceptive perceptions and cognitive functions. It implicates studies of inter-connected circuits and the need of explorations of roles of cerebellum in timing and plasticity.

\section{Acknowledgement}

This work derives direction and ideas from the Chancellor of Amrita University, Sri Mata Amritanandamayi Devi. This review was inspired by The School of Brain Cells and Circuits "Camillo Golgi" 2016 organized by Egidio D’Angelo of University of Pavia (Italy), Claudia Gandini Wheeler-Kingshott of UCL (UK) and gratefully acknowledge the support for our ongoing collaborations. Authors also thank Giovanni Naldi, Thierry Nieus of University of Milan (Italy) and Sergio Solinas of CNR (Sicily, Italy). This work is supported by Grants SR/CSRI/60/2013, SR/CSRI/61/2014 from DST and BT/PR5142/MED/30/764/2012 from DBT, and by Sir Visvesvaraya Faculty Fellowship, MeitY, Government of India and by Embracing the World. 


\section{References}

1. D’Angelo E (2015) The new challenge for Functional Neurology. Funct Neurol 30(4): 215.

2. D’Angelo E, Galliano E, De ZeeuwCI (2016) Editorial: The OlivoCerebellar System. Front Neural Circuits 9: 66.

3. Koziol LF, Budding D, AndreasenN, ArrigoSD, Schmahmann J, et al. (2013) Consensus Paper : The Cerebellum â€TM s Role in Movement and Cognition. Cerebellum 13(1): 151-177.

4. Berends M, Maex R, De Schutter E (2004) A detailed three-dimensional model of the cerebellar granular layer. Neuro computing 58-60: 587592.

5. Dell Nave R, Ginestroni A, Giannelli M, Tessa C, Salvatore E, et al. (2008) Brain structural damage in Friedreich's ataxia. J Neurol Neurosurg Psychiatry 79(1): 82-85.

6. Bhanpuri NH, Okamura AM, Bastian AJ (2013) Predictive Modeling by the Cerebellum Improves Proprioception. J Neurosci 33(36): 1430114306.

7. Piochon C, Kano M, Hansel C (2016) LTD-like molecular pathways in developmental synaptic pruning. Nat Neurosci 19(10): 1299-1310.

8. Flourens P (1858) De la vie et de l'intelligence, First ed Garnier Freres. Paris.

9. Albus JS (1971) A theory of cerebellar function. Math Biosci 10: 25-61.

10. Kawato M (1999) Internal models for motor control and trajectory planning. Curr Opin Neurobiol 9(6): 718-727.

11. Marr D (1969) A theory of cerebellar cortex. J Physiol 202(2): 437470.

12. Wolpert DM, Miall RC, Kawato M (1998) Internal models in the cerebellum. Trends Cogn Sci 2(9): 338-347.

13. Kawato M (2009) Cerebellum : Models Encycl Neurosci 2: 757-767.

14. Bostan AC, Dum RP, Strick PL (2010) the basal ganglia communicate with the cerebellum. Proc Natl Acad Sci U. S. A. 107(18): 8452-8456.

15. Stoodley CJ, Schmahmann JD (2009) Functional topography in the human cerebellum: a meta-analysis of neuroimaging studies. Neuroimage 44(2): 489-501.

16. D’Angelo E, Mazzarello P, Prestori F, Mapelli J, Solinas S, et al. (2011) The cerebellar network: From structure to function and dynamics. Brain Res Rev 66(1-2): 5-15.

17. Dean P, Porrill J (2011) Evaluating the adaptive-filter model of the cerebellum. J Physiol 589(14): 3459-3470.

18. Kawato M (1999) Internal models for motor control and trajectory planning. Curr Opin Neurobiol 9(6): 718-727.

19. Beaton A, Marien P (2010) Language cognition and the cerebellum: grappling with an enigma. Cortex 46(7): 811-820.

20. D’Angelo E, De Zeeuw CI (2009) Timing and plasticity in the cerebellum: focus on the granular layer. Trends Neurosci 32(1): 30-40

21. Lackner JR, Dizio P (1998) Gravitoinertial force background level affects adaptation to coriolis force perturbations of reaching movements. J Neurophysiol 80(2): 546-53.

22. Chen-HarrisH, Wilsim M Joiner, Vincent Ethier, David S Zee, Shadmehr R (2008) Adaptive Control of Saccades via Internal Feedback. J Neurosci 28(11): 2804-2813.
23. Pizoli CE, Jinnah HA, Billingsley ML Hess EJ, (2002) Abnormal cerebellar signaling induces dystonia in mice. J Neurosci 22(17): 7825-7833.

24. Shadmehr R, Mussa-Ivaldi F (1994) Adaptive representation of dynamics during learning of a motor task. J Neurosci 14(5): 32083224.

25. Catalan MJ, Ishii K, Honda M, Samii A, Hallett M (1999) A PET study of sequential finger movements of varying length in patients with Parkinson's disease. Brain 122 (3): 483-495.

26. Payoux P, Remy P, Damier P, Miloudi M, Loubinoux I, et al. (2004) Subthalamic nucleus stimulation reduces abnormal motor cortical over activity in Parkinson disease. Arch Neurol 61(8): 1307-1313.

27. Ghaemi M, Raethjen J, Hilker R, Rudolf J, Sobesky J, et al. (2002) Monosymptomatic resting tremor and Parkinson's disease: a multitracer positron emission tomographic study. Mov Disord 17(4): 782-788.

28. Rascol O, Agid Y, Damier P (2009) Contrasting changes in cortical activation induced by acute high-frequency stimulation within the globus pallidus in Parkinson's disease. J Cereb Blood Flow Metab 29(2): 235-243.

29. Turner RS, Grafton ST, McIntosh AR, DeLong MR, Hoffman JM (2003) The functional anatomy of parkinsonian bradykinesia. Neuroimage 19(1): 163-179.

30. Wu T, Hallett M (2005) A functional MRI study of automatic movements in patients with Parkinson's disease Brain 128(10): 2250-2259.

31. Yu H, Sternad D, Corcos DM, Vaillancourt DE (2007) Role of hyperactive cerebellum and motor cortex in Parkinson's disease. Neuroimage 35(1): 222-233.

32. Doya K (2000) Complementary roles of basal ganglia and cerebellum in learning and motor control. Curr Opin Neurobiol 10(6): 732-739.

33. Bosch-Bouju C, Hyland BI, Parr-Brownlie LC (2013) Motor thalamus integration of cortical, cerebellar and basal ganglia information: implications for normal and parkinsonian conditions. Front Comput Neurosci 7: 163.

34. Sherman SM, Guillery RW (2002) the role of the thalamus in the flow of information to the cortex. Philos Trans R Soc Lond B Biol Sci 357(1428): 1695-1708.

35. Asanuma K, Tang C, Ma Y, Dhawan V, Mattis P, et al. (2006)Network modulation in the treatment of Parkinson's disease. Brain 129(10): 2667-2678.

36. Geday J, Østergaard K, Johnsen E, Gjedde A (2009) STN-stimulation in Parkinson's disease restores striatal inhibition of thalamocortical projection. Hum Brain Mapp 30(1): 112-121.

37. Grafton ST, Turner RS, Desmurget M, Bakay R, Delong M, et al. (2006) Normalizing motor-related brain activity: subthalamic nucleus stimulation in Parkinson disease. Neurology 66 (8):1192-1199.

38. Hilker R, Voges J, Weisenbach S, Kalbe E, Burghaus L, et al. (2004) Subthalamic nucleus stimulation restores glucose metabolism in associative and limbic cortices and in cerebellum: evidence from a FDG-PET study in advanced Parkinson's disease. J Cereb Blood Flow Metab 24(1): 7-16.

39. Payoux P, Remy P, Miloudi M, Houeto JL, Stadler C, et al. (2009) Contrasting changes in cortical activation induced by acute highfrequency stimulation within the globus pallidus in Parkinson's disease. J Cereb Blood Flow Metab 29(2): 235-243. 
40. Krack P, Fraix V, Mendes A, Benabid AL, Pollak P (2002) Postoperative management of subthalamic nucleus stimulation for Parkinson's disease. Mov Disord 17 (3): 188-197.

41. Foit NA, van Velthoven V, Schulz R, Blümcke I, Urbach H, et al. (2016) Lesional cerebellar epilepsy: a review of the evidence. J Neurol 264(1): 1-10.

42. Boop S, Wheless J, Van Poppel K, McGregor A, Boop FA (2013) Cerebellar seizures. J Neurosurg Pediatr 12(3): 288-292.

43. Bai X, Vestal M, Berman R, Negishi M, Spann M, et al. (2010) Dynamic Time Course of Typical Childhood Absence Seizures: EEG Behavior and Functional Magnetic Resonance Imaging. J Neurosci 30(17): 5884-5893.

44. Casellato C, Antonietti A, Garrido J, a Carrillo RR, Luque NR, et al. (2014) Adaptive Robotic Control Driven by a Versatile Spiking Cerebellar Network. PLoS One 9(11): 112265.

45. Crunelli V, Cope DW, Terry JR (2011) Transition to absence seizures and the role of GABA (A) receptors. Epilepsy Res 97(3): 283-289.

46. D'Angelo E, Galliano E, De Zeeuw C (2016) Editorial: The OlivoCerebellar System. Front. Neural Circuits 9: 66.

47. Limousin-Dowsey P, Pollak P, Van Blercom N, Krack P, Benazzouz A, Benabid A (1999) Thalamic subthalamic nucleus and internal pallidum stimulation in Parkinson's disease. J Neurol 2: II42-5.

48. Kalanovic VD, Popovic D, Skaug NT (2000) Feedback error learning neural network for trans-femoral prosthesis. IEEE Trans. Rehabil Eng 8(1): 71-80.

49. Jayakar PB, Seshia SS (1987) Involuntary movements with cerebellar tumour. Can J Neurol Sci 14(3): 306-308.

50. Koh KN, Lim BC, Hwang H, Park JD, Chae JH, et al. (2010) Cerebellum Can Be a Possible Generator of Progressive Myoclonus. J Child Neurol 25(6): 728-731.

51. Mink JW, Caruso PA, Pomeroy SL (2003) Progressive myoclonus in a child with a deep cerebellar mass. Neurology 61(16): 829-831.

52. Strazzer S, Zucca C, Fiocchi I, Genitori L, Castelli E (2006) Epilepsy and neuropsychologic deficit in a child with cerebellar astrocytoma. J Child Neurol 21(9): 817-820.

53. Zamponi N, Passamonti C, Luzi M, Trignani R, Regnicolo L, Scarpelli M (2011) Fourth ventricle hamartoma presenting with progressive myoclonus and hemifacial spasms: case report and review of literature. Child's Nerv Syst 27(6): 1001-1005.

54. Shen G, Nan G, Shin CW, Park H, Lee KY (2016) Combined focal myoclonus and dystonia secondary to a cerebellar hemorrhage: a case report. BMC Neurol 16: 228.

55. Popa D, Spolidoro M, Proville RD, Guyon N, Belliveau L, et al. (2013) Functional Role of the Cerebellum in Gamma-Band Synchronization of the Sensory and Motor Cortices. J Neurosc 33(15): 6552-6556.
56. Proville RD, Spolidoro M, Guyon N, Dugué GP, Selimi Fet, et al. (2014) Cerebellum involvement in cortical sensorimotor circuits for the control of voluntary movements. Nat Neurosci 17(9): 1233-1239.

57. Neychev VK, Fan X, Mitev VI, Hess EJ, Jinnah HA (2008) The basal ganglia and cerebellum interact in the expression of dystonic movement. Brain 131(9): 2499-2509.

58. Hamandi K, Salek-Haddadi A, LaufsH, ListonA, Friston K, Fish DR Duncan, JS, Lemieux L (2006) EEG-fMRI of idiopathic and secondarily generalized epilepsies. Neuroimage 31(14): 1700-1710.

59. Holmes MD, Brown M, Tucker DM (2004) Are \& quot; Generalized \& quot; Seizures Truly Generalized? Evidence of Localized Mesial Frontal and Frontopolar Discharges in Absence. Epilepsia 45(12): 1568-1579.

60. Szaflarski JP, DiFrancesco M, Hirschauer T, Banks C, Privitera MD, et al. (2010) Cortical and subcortical contributions to absence seizure onset examined with EEG/fMRI. Epilepsy Behav 18(4): 404-413.

61. Westmijse I, Ossenblok P, Gunning B, van Luijtelaar G (2009) Onset and propagation of spike and slow wave discharges in human absence epilepsy: A MEG study Epilepsia 50(12): 2538-2548.

62. Rossi MA (2012) Deep white matter track record of functional integrity in childhood absence epilepsy. Epilepsy Curr 12(6): 234-235.

63. Qiu W, Gao Y, Yu C, Miao A, TangL, et al. (2016) Structural Abnormalities in Childhood Absence Epilepsy: Voxel-Based Analysis Using Diffusion Tensor Imaging. Front Hum Neurosci 10: 483.

64. Krook-Magnuson E, Szabo, GG, Armstrong C, Oijala M, Soltesz I (2014) Cerebellar Directed Optogenetic Intervention Inhibits Spontaneous Hippocampal Seizures in a Mouse Model of Temporal Lobe Epilepsy. e Neuro 1(1)

65. Eccles JC, Ito M, Szentágothai J (1967) The Cerebellum as a Neuronal Machine. Springer Berlin Heidelberg, Germany.

66. Ito M (2008) Control of mental activities by internal models in the cerebellum. Nat Rev Neurosci 9(4): 304-313.

67. Lackner JR, Dizio P (1994) Rapid adaptation to Coriolis force perturbations of arm trajectory. J Neurophysiol 72(1): 299-313.

68. Marr D (1969) A theory of cerebellar cortex. J Physiol 202(2): 437470.

69. Nave RD, Ginestroni A, Giannelli M, Tessa C, SalvatoreE, et al. (2008) Brain structural damage in Friedreich's ataxia. J. Neurol. Neurosurg. Psychiatry 79(1): 82-85.

70. Rascol O, Sabatini U, Fabre N, Brefel C, Loubinoux I, et al. (1997) The ipsilateral cerebellar hemisphere is overactive during hand movements in akinetic parkinsonian patients. Brain 120(1): 103-110.

71. Schmahmann JD, Caplan D (2006) Cognition, emotion and the cerebellum. Brain 129(2): 290-290. 